\title{
Imaged brine inclusions in young sea ice-Shape, distribution and formation timing
}

\author{
R.J. Galley ${ }^{\text {a,* }}$, B.G.T. Else ${ }^{\mathrm{e}}$, N.-X. Geilfus ${ }^{\mathrm{c}}$, A.A. Hare ${ }^{\mathrm{a}}$, D. Isleifson ${ }^{\text {a,d }}$, D.G. Barber ${ }^{\text {a }}$, S. Rysgaard ${ }^{\text {a,b,c }}$ \\ a Centre for Earth Observation Science, University of Manitoba, 125 Dysart Road, Winnipeg, Manitoba, Canada, R3T 2N2 \\ b Greenland Climate Research Center, Greenland Institute of Natural Resources, Kivioq 2, P.O. Box 570, 3900 Nuuk, Greenland \\ c Department of Bioscience, Arctic Research Centre, Aarhus University, 8000 Aarhus C, Aarhus, Denmark \\ d Department of Electrical Engineering and Computer Engineering, University of Manitoba, 75 Chancellor's Circle, Winnipeg, Manitoba, Canada, R3T 2N2 \\ e Department of Geography, University of Calgary, 2500 University Dr. NW, Calgary, Alberta, Canada, T2N 1N4
}

\section{A R T I C L E I N F O}

\section{Article history:}

Received 5 August 2014

Received in revised form 19 November 2014

Accepted 20 December 2014

Available online 24 December 2014

\section{Keywords:}

Arctic

Sea ice

Brine channels

Magnetic resonance imaging

Brine volume

\begin{abstract}
A B S T R A C T
Liquid inclusions in sea ice are variable and dependent on the myriad of physical conditions of the atmospheresea ice environment in which the sea ice was grown, and whether or not melting processes affected the sea ice. In that light, there exist relatively few observations and resultant quantification of the morphology and vertical distribution of brine inclusions in sea ice. Using a magnetic (3.0 T) resonance (MR) imager using constructive interference steady state gradient echo sequence, we show that it is possible to image brine channels and pockets in an $18.5 \mathrm{~cm}$ young sea ice core in three-dimensions in only four and a half minutes following core storage at $-20^{\circ} \mathrm{C}$. We present a three-dimensional image of a brine drainage channel feature in a young sea ice core, give the physical context for its formation by presenting the physical conditions of the atmosphere and water/sea ice prior to sea ice growth through the sampling date, and observe its physical characteristics. We illustrate that brine drainage channels may be established concurrently with ice growth, and indicate the amount and location of vertical and horizontal fluid connectivity in the young sea ice sample in the context of the environment in which it grew. Finally, we show that a vertical brine volume distribution profile can be calculated using MR image data, extending the (non-imaging) nuclear magnetic resonance work of others in this vein.
\end{abstract}

(c) 2014 Elsevier B.V. All rights reserved.

\section{Introduction}

The crystal structure of sea ice and its inclusions control its mechanical strength (Assur, 1960), and its ability to exchange heat, salt and radiation (Light et al., 2003), which in turn affect the atmosphere above and the ocean below, physically, chemically (Vancoppenolle et al., 2013) and biologically (Fritsen et al., 1994; Krembs et al., 2000). The apparent optical properties of sea ice are contingent on the distribution of gas and liquid inclusions and the electromagnetic properties of sea ice are governed by the size, shape, and orientation of these inclusions. Therefore, improved knowledge of these properties is required for interpreting sea ice scattering signatures obtained using remote sensing techniques (Tucker et al., 1992). Liquid inclusions in sea ice largely determine the volumes' heat capacity and permeability (e.g. Golden et al., 1998, 2007; Weeks and Ackley, 1982), which controls bulk flow in the volume and may act to flood the sea ice surface from below, or drain the sea ice volume to the ocean (e.g. Vancoppenolle et al., 2007). Brine drainage channels are very important, as they are likely the sites of the bulk of the liquid convection (i.e. gravity drainage) to the sea ice-seawater interface (Eide and Martin, 1975; Lake and Lewis, 1970;

\footnotetext{
* Corresponding author.

E-mail address: ryan.galley@ad.umanitoba.ca (R.J. Galley).
}

Niedrauer and Martin, 1979; Notz and Worster, 2008; Oertling and Watts, 2004; Untersteiner, 1968; Weeks and Ackley, 1986). Notz and Worster (2009) conclude that brine drainage is governed by the sea ice thickness, permeability, and the established brine density gradient.

Observations by Bennington (1967) using ice samples $50 \mathrm{~cm}$ (December), $120 \mathrm{~cm}$ (January) and $160 \mathrm{~cm}$ (February) thick over the winter of 1964/1965 indicate that brine drainage channels formed during ice growth (termed first-generation drainage channels) are conically shaped, interconnected networks of brine pockets between platelets; a second type of channel with similar morphology is characteristic of melting sea ice (termed second-generation brine drainage channels). Lake and Lewis (1970) showed that sea ice near the seawater interface was partly composed of vertical tubular structures attended at angles of $40^{\circ}-54^{\circ}$ by smaller tributary channels which often followed crystal boundaries (sample thickness $=155 \mathrm{~cm}$ ). That range of angles was later expanded to $30^{\circ}-60^{\circ}$ by Niedrauer and Martin (1979) in microcosm experiments with $\mathrm{NaCl}$ ice, and corroborated by Kovacs (1996) and Cole and Shapiro (1998) in medium and thick first year ice. These 'starburst patterns' when looked on from above, had a mean diameter of $4 \mathrm{~cm}$ and the individual feeder channels were $2-3 \mathrm{~cm}$ long and 2$8 \mathrm{~mm}$ in diameter (Lake and Lewis, 1970), indicating the potential for horizontal brine movement within sea ice toward preferred vertical drainage areas, though no mention was made of when or how fast 
they formed. Lake and Lewis (1970) also found the largest, most well developed inclusions in the bottom $20 \mathrm{~cm}$ of their ice samples ( $13 \%$ of a $1.55 \mathrm{~m}$ sample thickness), noting that higher, diffuse structures were most likely remnants left by past ice growth.

More recently, the model of Wells et al. (2011) tested against the experimental results of Wettlaufer et al. (1997) predicts regions of low solid fraction close to brine channel walls where feeder channels were observed by Lake and Lewis (1970). This suggests that the exchange of liquid between ocean and sea ice occurs by convective brine drainage, which was also observed in freezing sucrose solutions by Aussilous et al. (2006) and by Notz and Worster (2009) using bulk sea ice electrical impedance measurements.

Eicken et al. (2000) used MR imaging as a method for the characterization of the microstructural evolution of sea ice inclusions. The authors presented sequential images of horizontal thin sections as they warmed, though individual samples took between four and 12 hours and required the use of temperature controlled infrastructure in the MR imager (Eicken et al., 2000). Using Nuclear Magnetic Resonance (NMR), Mercier et al. (2005) showed isotropy and anisotropy in sea ice diffusion coefficients. Callaghan et al. (1999) and Hunter et al. (2009) showed the NMR technique well-replicated calculated brine volume fractions in sections of Antarctic sea ice up to $220 \mathrm{~cm}$ thick and $180 \mathrm{~cm}$ thick respectively. However, the NMR technique is unable to determine pore sizes, shapes, or distribution within the sea ice, highlighting the need for a greater library of physical observations of liquid inclusions in sea ice under a variety of sea ice types/environments (e.g. Hunke et al., 2011).

Here we endeavour to add a three-dimensional image of a brine drainage channel feature in young sea ice $(18.5 \mathrm{~cm}$ thick) to the literature using an imaging sequence that was performed with a standard human MR imager in as little as $4 \mathrm{~min}$ and $30 \mathrm{~s}$. We present observations of the physical characteristics of the brine drainage channel, and discuss the atmospheric, seawater, and sea ice conditions under which it formed. Finally, we present a vertical brine volume distribution profile of our sea ice sample using MR image data to extend the (non-imaging) nuclear magnetic resonance work of others.

\section{Methods}

In December 2011 and January 2012, a sea ice growth experiment was conducted at the Sea-ice Environmental Research Facility (SERF) at the University of Manitoba. The SERF is an $18.2 \mathrm{~m}$ (length) by $9.1 \mathrm{~m}$ (width) by $2.75 \mathrm{~m}$ (depth) outdoor pool filled with artificial seawater similar in composition to natural average seawater (see Hare et al., 2013 for a chemical analysis of the seawater composition, after Millero, 2006). Impurities of course occurred in the commercial salts used to formulate the seawater, and those left undissolved could be seen suspended in the water column at the beginning of the experiment. The experiment began on 22 December 2011 by allowing the pool to cool by turning off its heating system. The sea ice in the SERF was initially allowed to form in the absence of wind forcing and snow accumulation to ensure uniform ice formation and growth over the entire pond area $\left(\sim 165 \mathrm{~m}^{2}\right)$ using the facility's retractable roof to shield the ice surface. Though the sea ice was initially grown in the absence turbulent forcing, the conditions under which it formed yielded young sea ice that was physically and chemically similar to natural Arctic sea ice (e.g. Geilfus et al., 2013b; Hare et al., 2013; Rysgaard et al., 2014).

The 2-m air temperature over the pool surface was recorded using a Vaisala HMP45C probe enclosed in a radiation shield connected to an automated station logger. Seawater and later sea ice and seawater temperatures through the depth of the pool were measured by the same automated station using type-T thermocouples (Omega Engineering, USA) placed in the pool at $5 \mathrm{~cm}$ intervals from 0 to $1.2 \mathrm{~m}$ and at $20 \mathrm{~cm}$ intervals from $1.2 \mathrm{~m}$ to $2.4 \mathrm{~m}$ to show general warming and cooling timing and trends in the volume (Fig. 1).

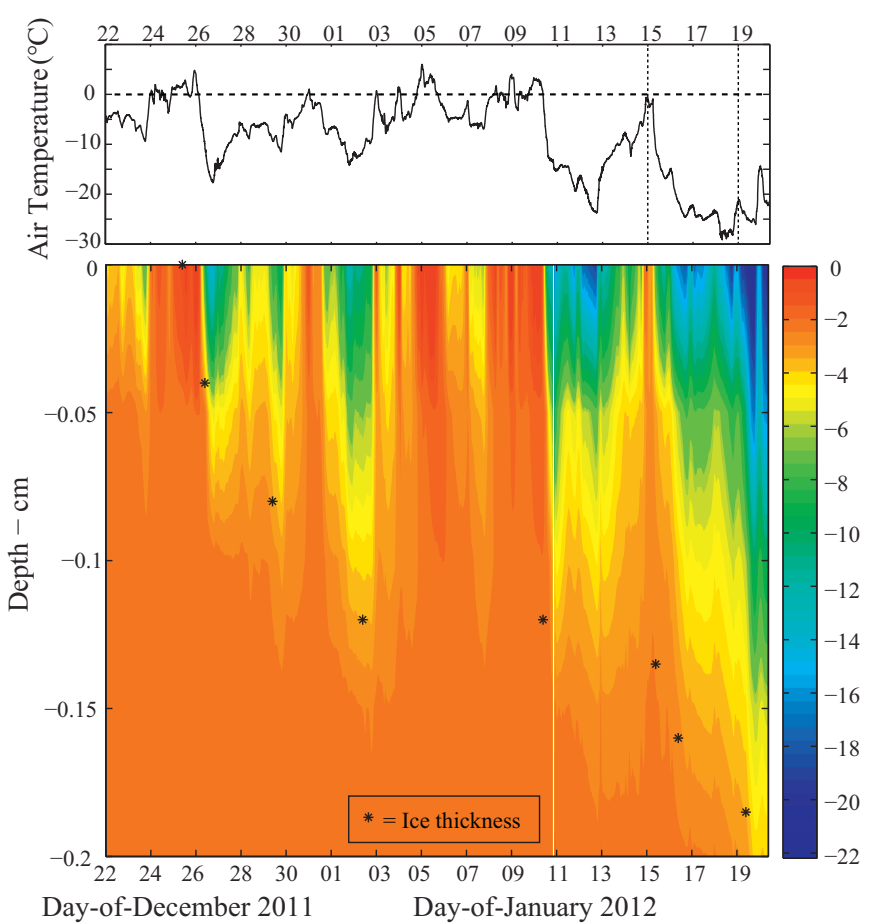

Fig. 1. (Top) 2-m air temperature and (bottom) sea ice and water temperature for the duration of the ice growth experiment overlain by ice thickness measurements. A vertical dashed line in the air temperature panel indicates two snow or blowing snow events.

No sea ice samples were taken prior to 11 January to ensure a uniform and undisturbed sea ice volume at least $10 \mathrm{~cm}$ thick (Fig. 2a). Sea ice samples were extracted on 11, 16 and 20 January using a Kovacs Mark II ice coring system. One core sample each day was cut into $2-\mathrm{cm}$ thick sections, which were melted in sealed buckets. Bulk salinity of these sections was determined by measuring the conductivity and temperature of the melt using a Hach SensION 5 conductivity probe. These salinity data are presented with the caveat that this method may underestimate the actual bulk salinity (e.g. Notz et al. (2005)) of relatively warm young sea ice. Storage has also been shown to have an effect on sea ice bulk salinity when measured this way (e.g. Cox and Weeks, 1986) though our cores were not stored frozen and were analyzed within hours of their melting.

A second core on each date was used to determine the sea ice temperature immediately upon extraction at the mid-point of each $2 \mathrm{~cm}$ thickness subsample using a digital thermometer (Traceable Control Company, Model 4000, accuracy $= \pm 0.05{ }^{\circ} \mathrm{C}$ ). Pringle and Ingham (2009) propose that temperature measurements using extracted cores should be done within $5 \mathrm{~min}$, noting that the accuracy of these measurements can easily be less than $0.5^{\circ} \mathrm{C}$ (e.g. Eicken et al. (2004) achieved an accuracy of $0.2^{\circ} \mathrm{C}$ ). Using the in situ temperatures and bulk salinity data from the cores, the brine volume was calculated using the equation of Cox and Weeks (1983) assuming a density of $917 \mathrm{~kg} \mathrm{~m}^{-3}$ (these equations may underestimate in situ brine volume of sea ice, especially for high brine volumes and/or warm in situ sea ice temperatures due to brine loss upon core extraction). On 20 January a third core was retrieved and was immediately stored at $-20{ }^{\circ} \mathrm{C}$ for MR imaging. In the absence of a method that preserves the natural temperature gradient within sea ice immediately and without change upon extraction, ex situ analysis of sea ice samples after storage at low temperatures is an established protocol. For example, Eicken et al. (2000) and Bock and Eicken (2005) based their conclusions regarding sea ice microstructural evolution with temperature under the assumption that cores stored at low $\left(<-20^{\circ} \mathrm{C}\right)$ temperatures then subsequently warmed as they were imaged behave similarly to sea ice in the natural system. 
a

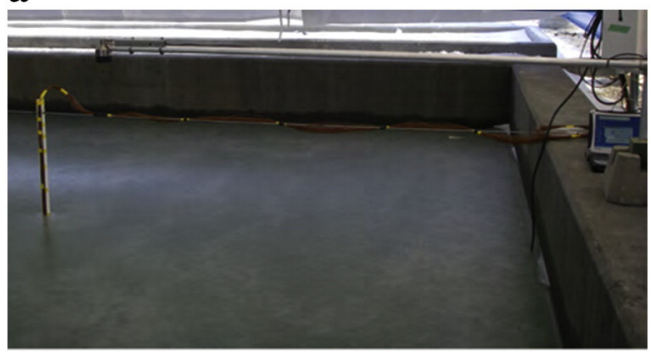

b

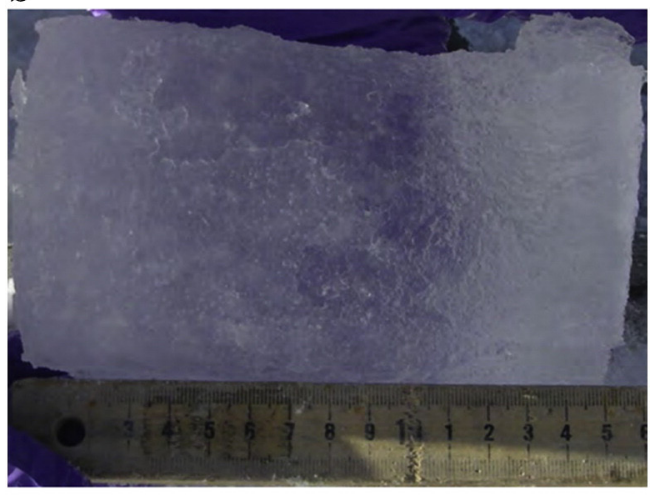

c

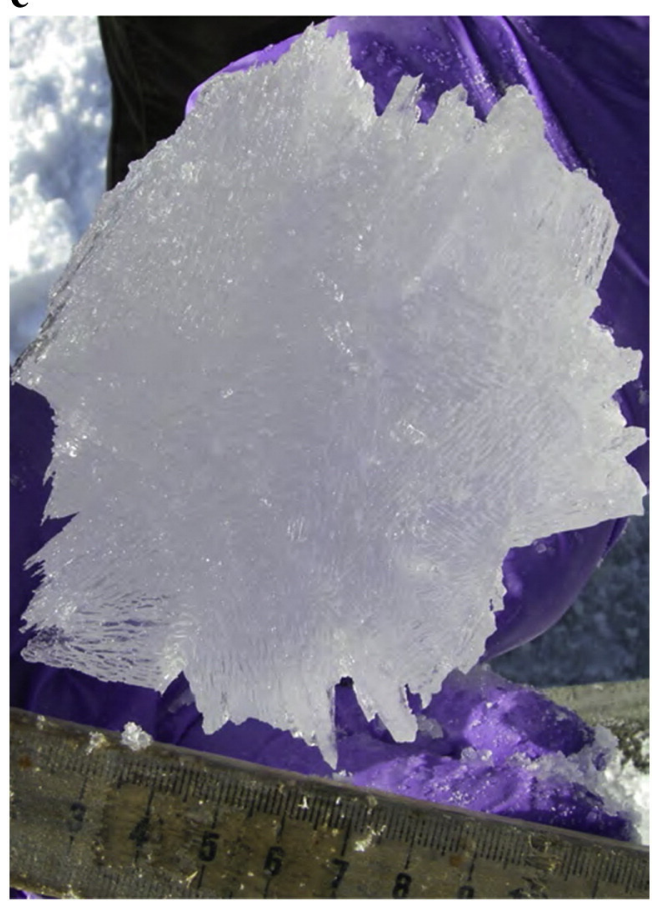

Fig. 2. (a) Oblique view of the sea ice in SERF as it transitioned to light nilas around 3 Jan 2013, (b) side view (sea ice top at left) of a sea ice core sample on 16 Jan 2012 showing between 4 and $5 \mathrm{~cm}$ of granular ice growth followed by columnar sea ice growth about $10 \mathrm{~cm}$ in thickness, (c) bottom view of the a sea ice core on 20 Jan showing columnar ice growth with randomly oriented c-axes.

On 20 March 2012 a Siemens 3.0 T TIM TRIO human MRI scanner (Siemens Medical Solutions Inc.) located at the Canadian National Research Council Institute for Bio-diagnostics was employed to image the third replicate sea ice core sample of 20 January. The sea ice core sample was stored horizontally at $-20{ }^{\circ} \mathrm{C}$ following its extraction from the SERF, then transported in a portable cooler filled with ice packs to the MRI facility where it was placed in the MR scanner in a chilled $\left(-20^{\circ} \mathrm{C}\right)$ towel inside a standard head-imaging coil. The towel served as insulation and to ensure the core fit snugly to eliminate any movement during imaging. The MR instrument created a 72-image sequence of the ice core sample using a constructive interference steady state (CISS) gradient echo sequence, to create high-resolution 3dimensional image dataset. The principle advantage of this sequence is its combination of high signal levels and extremely high spatial resolution. A repetition time (TR) of $5.93 \mathrm{~ms}$ and an echo time (TE) of $2.83 \mathrm{~ms}$ were employed, yielding a total scanning time of 4 min $30 \mathrm{~s}$. Although much longer TR and TE have been employed previously to image sea ice samples (in part to characterize temporal changes and in part to maximize resolution, see for e.g. Eicken et al., 2000) it was necessary to keep the scanning time very short as a result of the lack of sample refrigeration in the MR imager. The 72-image sequence was limited the imaging the interior $28.8 \mathrm{~mm}$ of the $90 \mathrm{~mm}$-diameter core sample, excluding imagery of nearly all of the outside surface of the core, greatly reducing the possibility that surface melt was imaged during the 4 minute and 30 second scan. The vertical (Y) and horizontal (X) resolution of each image was 320 by 240 pixels, each of which was $0.623 \mathrm{~mm} \mathrm{x}$ $0.623 \mathrm{~mm}$ resulting in a two-dimensional pixel resolution of $=$ $0.388 \mathrm{~mm}^{2}$. Each of the 72 images integrated a slice thickness $(Z)$ of $0.4 \mathrm{~mm}$ making the voxel (three-dimensional pixel) resolution $0.155 \mathrm{~mm}^{3}$.

Due to the interaction of the magnetic field with protons (water), MR images are a representation of liquid content within voxels expressed as digital numbers (DN). The distribution of voxel DNs showed a clear saturation at $\mathrm{DN}=39$, the maximum voxel return, $V_{\max }$. Several of the imaged liquid structures were much larger in volume than an individual voxel, leading us to conclude that $V_{\max }$ represents a pure, or $100 \%$ liquid water fraction $\left(L_{f}\right)$. Therefore, the $L_{f}$ of any voxel $\mathrm{DN}\left(V_{D N}\right)$ can be calculated by

$L_{f}=\frac{V_{D N}}{V_{\max }} \times 100$

to quantify the liquid fraction at depth in the core sample. We define this relationship as linear based on the work of Callaghan et al. (1999), who made a linear regression analysis of NMR-derived brine volume and brine volume calculated using the equation of Cox and Weeks (1983) yielding a correlation coefficient of 0.952. We calculated the liquid water fraction for every voxel to create a liquid volume profile analogous to a brine volume profile derived using temperature and bulk salinity measurements from a traditionally sectioned core, but at a much higher $(0.623 \mathrm{~mm})$ vertical $(\mathrm{Y})$ resolution. Since the sea ice core temperature was imaged at $-20{ }^{\circ} \mathrm{C}$ we calculated brine volume at that temperature throughout the core.

\section{Results and discussion}

\subsection{Environmental conditions, sea ice growth and physical properties}

Relatively warm air temperatures on 22 December 2011 (Fig. 1) cooled the water column slowly at first, before a rapid decrease to $-18^{\circ} \mathrm{C}$ in the afternoon of 26 December initiated frazil ice growth likely seeded by impurities in the water as a result of the artificial seawater production process. The sea ice thickness reached $4 \mathrm{~cm} 30 \mathrm{~h}$ later on 27 December 2011 and continued to thicken until about 3 January 2012 when it reached $12 \mathrm{~cm}$ (Fig. 1). Observation of core samples indicates that a 4-5 cm granular layer was present (e.g. Fig. 2a and b) below which the ice transitioned to congelation growth (e.g. Fig. 2c).

Between 3 and 10 January, the air temperature fluctuated near $0{ }^{\circ} \mathrm{C}$ warming the sea ice and resulting in zero net ice growth (Fig. 1). The sea ice was $12 \mathrm{~cm}$ thick on 11 January, and had a c-shaped bulk salinity profile; the sea ice salinity was near 8 in the top-most 2-cm section before decreasing to less than 4 in the $2 \mathrm{~cm}-4 \mathrm{~cm}$ section before increasing to about 7 in the bottommost $2-\mathrm{cm}$ section (Fig. 3b). Brine volume calculated using in situ temperatures indicate that on 11 January the 

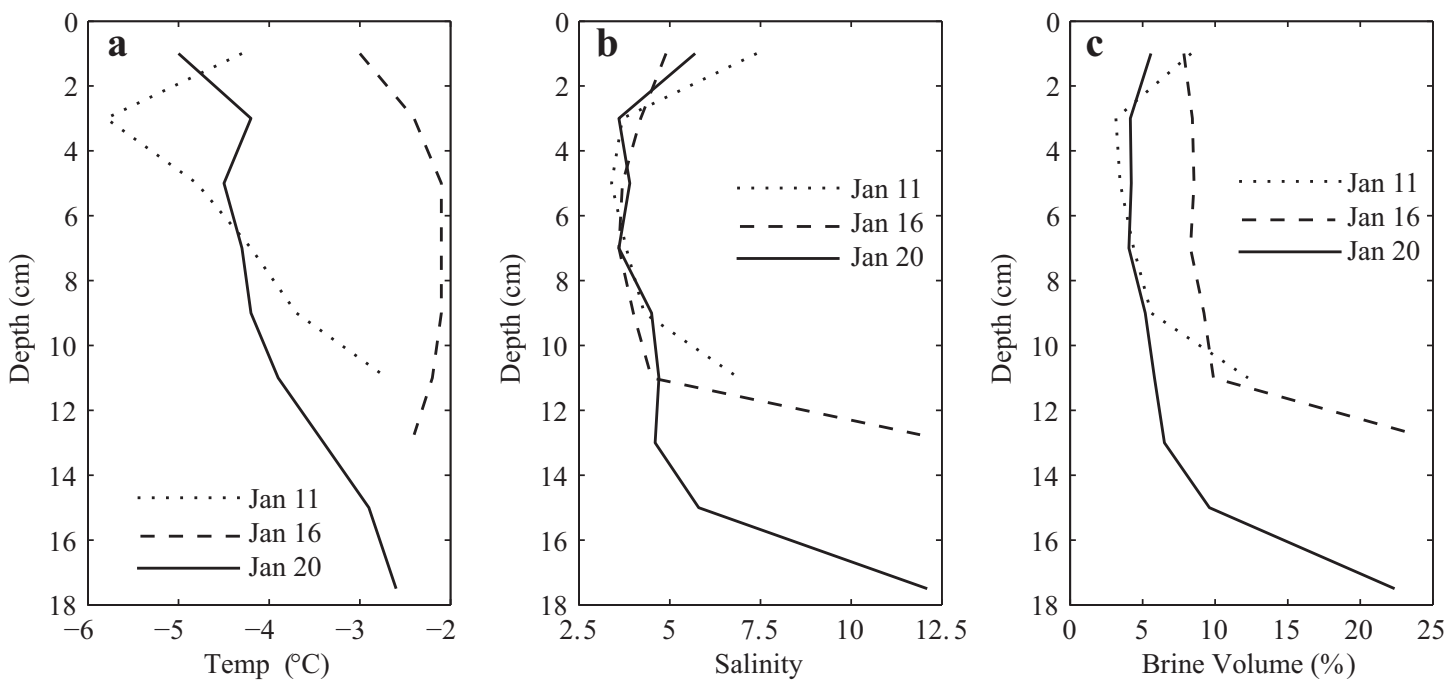

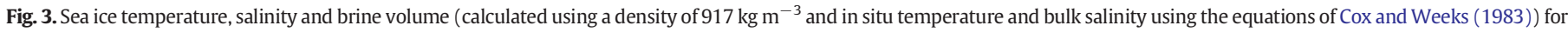
11 January (dotted lines), 16 January (dashed lines) and 20 January 2012 (solid lines).

topmost section of sea ice was nearly $10 \%$ brine-by-volume, and decreased below $5 \%$ above the $10 \mathrm{~cm}$ depth before increasing again to nearly $15 \%$ in the bottommost 2-cm section (Fig. 3c).

On 12 January 2012 the roof covering the pool was retracted exposing the sea ice surface to the ambient wind, radiation and snowfall conditions. The air temperature cooled to $-22{ }^{\circ} \mathrm{C}$ near midnight on 12 January, which cooled the ice volume, but it took until the morning of 15 January for the thickness to reach $13 \mathrm{~cm}$, a $1 \mathrm{~cm}$ thickness increase in almost four days (Fig. 1). Early on 15 January the air temperature increased rapidly to near $0{ }^{\circ} \mathrm{C}$ (Fig. 1 ) during a low-pressure disturbance, which also saw snowfall and blowing snow that deposited $2-3 \mathrm{~cm}$ snow on the sea ice surface, causing a rapid increase in the sea ice temperature (Fig. 1). The sea ice temperature increase was likely caused in part by depression of the floating sea ice into the warmer water below and in part by warm air temperatures. Following passage of the low on 15 January, the air and sea ice temperatures cooled. On 16 Jan, the sea ice was $13.5 \mathrm{~cm}$ thick (Fig. 1) and had a c-shaped bulk salinity profile. The bulk salinity of the topmost 2-cm section had decreased to less than 5 , while the bottommost $1.5-\mathrm{cm}$ section had a bulk salinity of about 8 (Fig. 3b). The sea ice brine volume was nearly constant about $9 \%$ save for the bottommost 2-cm layer on 16 January owing to a nearly isothermal sea ice volume warmer than $-3{ }^{\circ} \mathrm{C}$ (Fig. 3a) caused by a sharp increase in the air temperature (Fig. 1). Sea ice sample pictures following 16 January indicate that the top $4.5 \mathrm{~cm}$ of the sea ice thickness were due to frazil growth into grease ice, which capped the pond (Fig. 2a and b) and then finally into columnar nilas sea ice with randomly oriented c-axes (e.g. Fig. 2c). The sea ice samples of 20 January 2012 were $18.5 \mathrm{~cm}$ thick, though analysis of cores taken over the experiment suggest some spatial variation $( \pm 1.0 \mathrm{~cm})$ existed in the sea ice thickness within the facility.

On 20 January, several days of air temperatures less than $-20^{\circ} \mathrm{C}$ and a $2-3 \mathrm{~cm}$ snow cover meant a temperature gradient from $-5.4^{\circ} \mathrm{C}$ at the surface of the sea ice to $-2.3{ }^{\circ} \mathrm{C}$ nearest the sea ice-seawater interface (Fig. 3a). The in situ sea ice temperature profile of 20 January shows near-surface warming near a depth of $4 \mathrm{~cm}$ that is likely a product of diurnal temperature changes. The sea ice bulk salinity profile on 20 January 2012 was generally c-shaped, but contained an inflection toward higher bulk salinity between the $6-8$ and $12-14 \mathrm{~cm}$ layers (Fig. $3 \mathrm{~b}$ ). The brine volume curve is shaped similarly to the bulk salinity curve (Fig. 3c).

In summary, the top $12 \mathrm{~cm}$ of the sea ice sampled on 20 January were grown steadily between 26 December 2011 and 3 January 2012. This $12-\mathrm{cm}$ thick sea ice then underwent a warming period between 3 and 10 January 2012 during which no net change in its thickness occurred (Fig. 1). Between 11 and 16 January the bulk salinity values in the sea ice decreased though the brine volumes between 2 and $10 \mathrm{~cm}$ depths increased (Fig. 3c) when snow and blowing snow accumulated on top of the ice and the air temperature rose to nearly $0{ }^{\circ} \mathrm{C}$ on $15 \mathrm{Jan}$ uary, warming the now $13.5 \mathrm{~cm}$-thick sea ice (Fig. 1). Low air temperatures between 16 and 20 January caused the sea ice to grow from $13.5 \mathrm{~cm}$ to $18.5 \mathrm{~cm}$ thick, resulting in slightly increased bulk salinity in the lower part of the ice, and lower brine volumes in the top $16 \mathrm{~cm}$ layer but high brine volumes in the bottom 2.0-2.5 cm-layer (Fig. 3).

\subsection{3-D MR images of brine inclusions}

Three-dimensional images showing the morphology and location of liquid inclusions in the sea ice core sample of 20 January using a highresolution CISS gradient echo image MR sequence are shown in Fig. 4; this MR sequence took only $4 \mathrm{~min}$ and $30 \mathrm{~s}$. Guided by the growth history of the sea ice (Figs. 1, 3) and evidence of a $4-5 \mathrm{~cm}$ granular sea ice cap on top of predominately congelation ice growth (Fig. 2), the top section of our sample core is $50 \mathrm{~mm}$ thick and is comprised mainly of spherical inclusions that are randomly distributed and less than $2 \mathrm{~mm}$ in diameter, though a few are as large as $3 \mathrm{~mm}$ in diameter (Fig. 4). The position and distribution of the inclusions are illuminated in horizontal sub sections $(240(\mathrm{X}) \times 72(\mathrm{Z})$ pixels $)$ using the sum of 6 image rows $(\mathrm{Y}$, $3.738 \mathrm{~mm}$ total thickness) (Fig. 5). In the top section (56.07 mm thick integrating 90 image rows, Fig. 5a), we observe small spherical and oblong inclusions in the first $29.90 \mathrm{~mm}$ of the sea ice core (Fig. 5a). The inclusions above $29.90 \mathrm{~mm}$ depth do not appear to be vertically developed by more than the thickness of one MR sub section (3.738 mm). Between $29.90 \mathrm{~mm}$ and $48.59 \mathrm{~mm}$, the imaged inclusions are mainly spherical and larger than those in the top $29.90 \mathrm{~mm}$; the largest inclusion, most easily seen in MR sections centered on 37.38 and $41.12 \mathrm{~mm}$ (Fig. 5a) is 5.5-6.5 mm in diameter. Above this inclusion and centered on $33.64 \mathrm{~mm}$ in the top granular section (Fig. 2b), there are several similar inclusions, though not quite as large, with diameters between 3.5 and $4.5 \mathrm{~mm}$ (Fig. 5a) arranged in a circular starburst pattern. This may indicate this portion of the sea ice volume once contained a brine channel feature similar to the one imaged in the bottom part of the core (Fig. 5c) that is no longer connected to the sea ice-seawater interface, trapped within the volume as individual inclusions by reduction in its volume due to decreased temperatures as the ice thickened or lost during desalination of this portion of the sea ice when its growth stagnated between 3 and 10 January. This observation supports the 

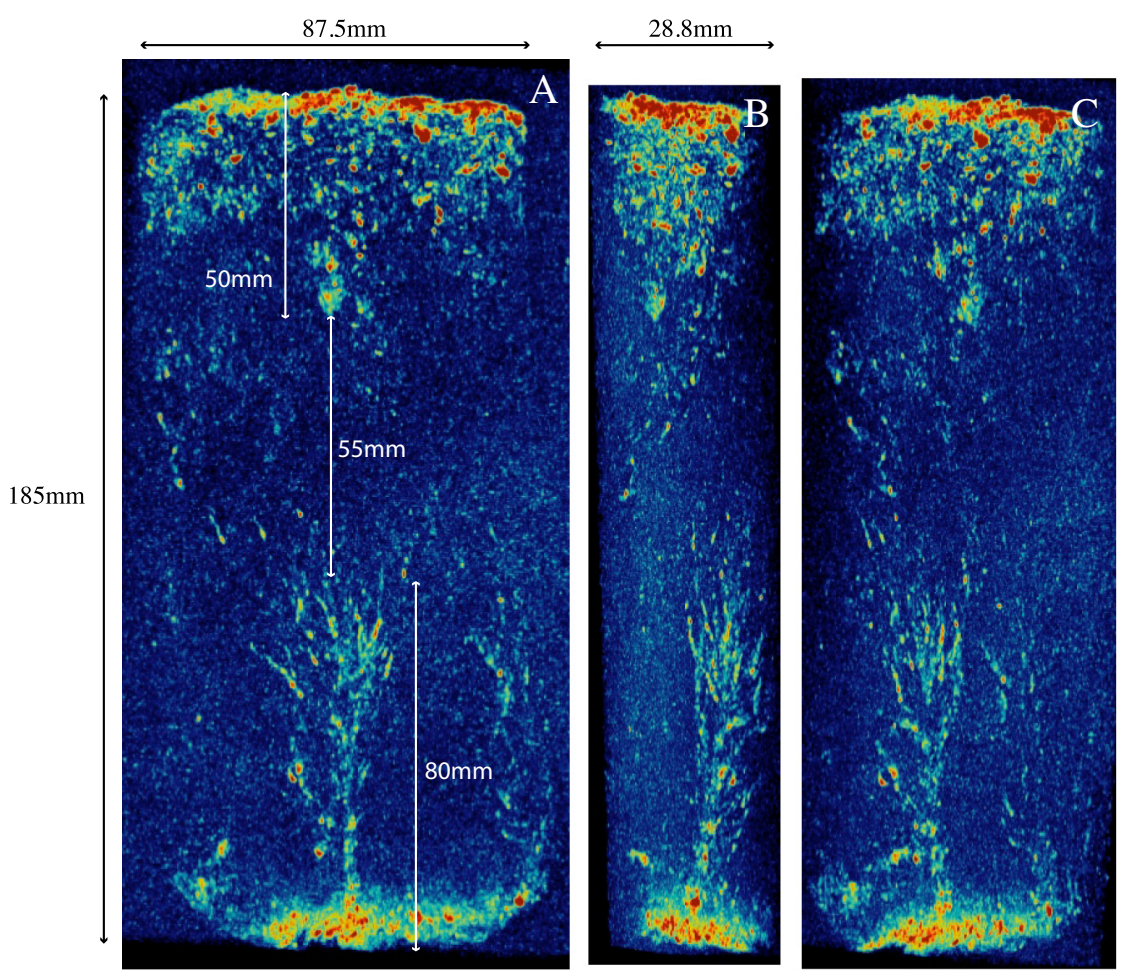

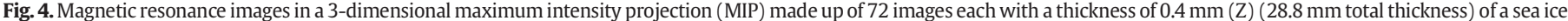
core $($ depth $(\mathrm{Y})=186 \mathrm{~mm}$, diameter $=87.5 \mathrm{~mm}$ ) viewed from the front (LEFT), side (MIDDLE) and rotated obliquely (RIGHT).

observation of Cole and Shapiro (1998) that large drainage networks with similar geometry terminate at various horizons in thick first year sea ice; further, our data shows this begins to occur very shortly after the sea ice formation. It does not appear that the top section of the sea ice sample volume could be connected to the sea ice-seawater interface on 20 January due to the shapes and lack of connectivity of the imaged liquid inclusions and granular crystal structure.

The middle section of the core is about $55 \mathrm{~mm}$ thick, and contains very few imaged inclusions (Fig. 4). Inclusions in this section are generally elongated between $25^{\circ}$ and $30^{\circ}$ from the vertical. Beginning at $52.33 \mathrm{~mm}$ depth (Fig. 5a) and continuing downward through the middle part of the core (Fig. 5b) there are no obvious inclusions of the same magnitude as those in the top section, which is reasonable given the relatively low bulk salinity and brine volumes observed in this section of the core on 20 January (Fig. 3b, c). This desalination was likely the product of warm sea ice temperatures below the surface layer (Fig. 3a) and $2-3 \mathrm{~cm}$ of snow insulation at the surface eliminating sea ice growth between 3 and 10 Jan and retarding the growth rate substantially between 15 and 20 January (Fig. 1). Eicken (1992) showed that increased snow accumulation and/or increased ocean heat flux result in increased thermal insulation and decreased growth rates, which reduced bottom salinities. We propose that the sea ice temperatures presented here between 3 and 10 January were warm enough to partly desalinate the sea ice volume below $5 \mathrm{~cm}$ depth, reducing greatly the presence of liquid inclusions found in the MR image of the volume on 20 January (Fig. 4). Fig. 3b also indicates that the $2-\mathrm{cm}$ sections centered on depths of 5,7 and $9 \mathrm{~cm}$ desalinated between 11 and 16 January and between 16 and 20 January. These results combined with the absence of imaged inclusions between 5 and $10 \mathrm{~cm}$ (Figs. 4, 5b) may indicate that a brief warming period which occurred prior to 15 January and snow accumulation on 15 January (Fig. 1) may have helped retard the sea ice growth rate between about 12 and 15 January, further desalinating the sea ice volume below $5 \mathrm{~cm}$.

The bottom section $(\sim 80 \mathrm{~mm}$ in height $)$ contained a brine drainage channel structure (Fig. 4), $80 \mathrm{~mm}$ in height from the bottom of the sea ice core with its widest point ( $40 \mathrm{~mm}$ wide) $65 \mathrm{~mm}$ from the bottom of the core. It is wider in the X-plane than in the Z-plane (Fig. 4). The brine drainage channel feature imaged here in young sea ice takes the shape of a "river attended to by its tributaries" (after Lake and Lewis, 1970 who observed these features in $1.55 \mathrm{~m}$ thick sea ice) in the vertical, with the attending channels and elongated pockets intersecting the main vertical channel at angles less than $35^{\circ}$ (all angles are from the vertical), though there is one channel about $30 \mathrm{~mm}$ in length which connects at an angle of approximately $55^{\circ}$ (Fig. 4). These attending channels were measured individually using OsiriX software and found to be within $0.80 \mathrm{~mm}$ and $1.5 \mathrm{~mm}$ in diameter. The time which the brine drainage channel feature took to form was less than six days, as the sea ice in the SERF pond was $\sim 13 \mathrm{~cm}$ thick on 15 January and grew to $18.5 \mathrm{~cm}$ thick on 20 January 2012 (Fig. 1), making it a firstgeneration brine drainage feature in the nomenclature of Bennington (1967) formed during congelation sea ice growth (Figs. 2c, 5c). The presence of this feature indicates that the depth of the permeable layer is about $43 \%$ of the total thickness (i.e. 80 of 185 total $\mathrm{mm}$ ) in this young sea ice core. Below $10 \mathrm{~cm}$ thickness, the sea ice on 20 January was warm, with bulk salinities near 5 or greater (Fig. 3b), and brine volumes (from the Cox and Weeks, 1983 equation) greater than 5 (Fig. 3c).

To characterize the brine drainage channel features that occupy part of the bottom $80 \mathrm{~mm}$ of our sea ice core, ten horizontal sections comprising the sums of twelve horizontal slices are presented in Fig. 5c. The bottom-most section centered at $178.80 \mathrm{~mm}$ depth shows similarly oriented groups of columnar crystal lamellae with liquid between them (Fig. 5c, and see for e.g. Fig. 2c). In the section centered at $171.33 \mathrm{~mm}$ (Fig. 5c), the brine drainage channel outlet is resolved, which is $4.4 \mathrm{~mm}$ by $3.1 \mathrm{~mm}\left(13.7 \mathrm{~mm}^{2}\right)$. In the horizontal sections at $163.85 \mathrm{~mm}$ and $156.37 \mathrm{~mm}$ depth, the brine drainage channel is seen to split in two. The brine drainage feature is then observed to branch out before taking the "starburst" shape in the section at $133.95 \mathrm{~mm}$ (Fig. 5c). We draw the comparison between this section in the bottom part of the core, and the section centered on $33.64 \mathrm{~mm}$ (Fig. 5a) noting they look very similar, though their connections through the sea ice above and below them are different. Above $113.95 \mathrm{~mm}$ (Fig. 5c), the 


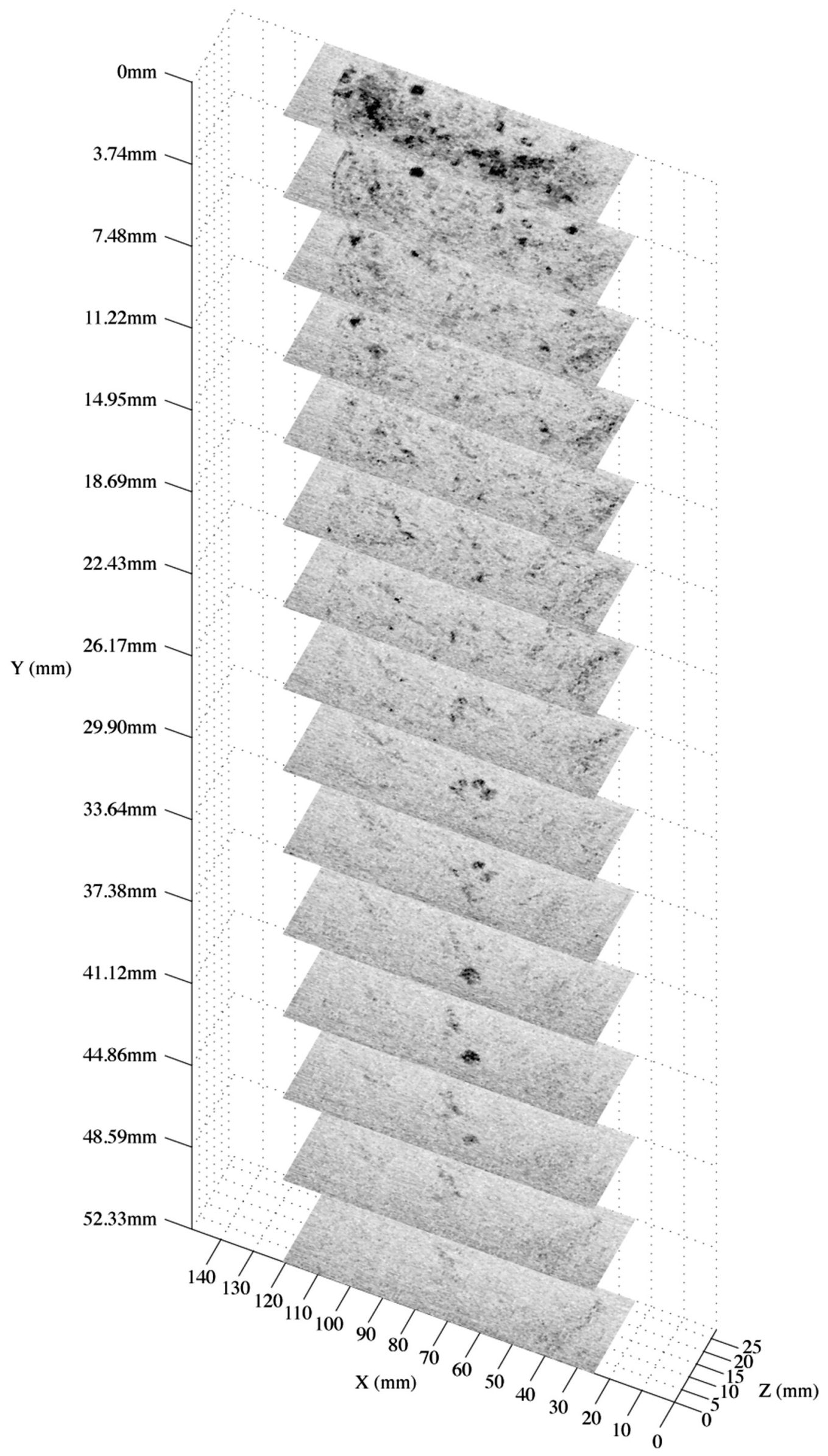




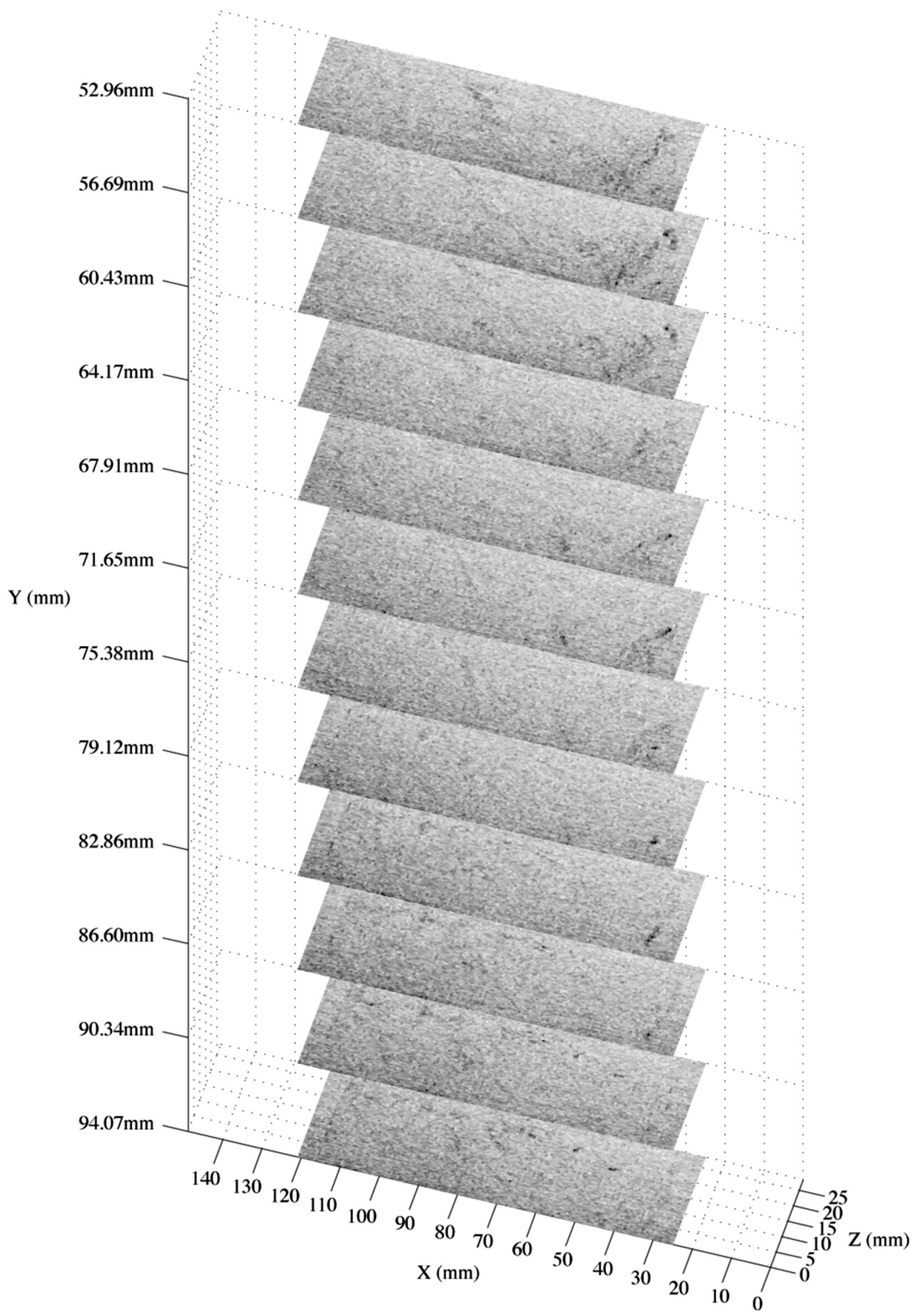

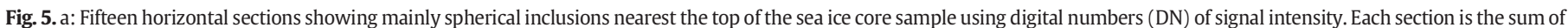

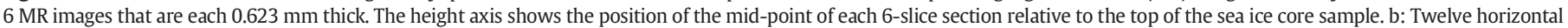

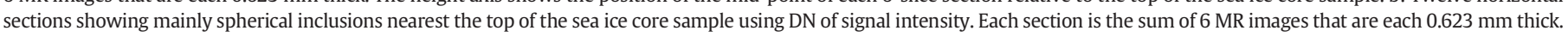

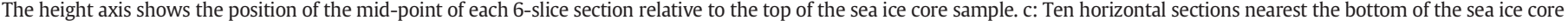

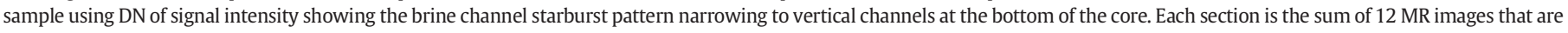
each $0.623 \mathrm{~mm}$ thick. The height axis shows the position of the mid-point of each 12-slice section relative to the top of the sea ice core sample.

feeder arms which connect these horizontal sections vertically become more diffuse, and at $111.52 \mathrm{~mm}$ (Fig. 5c) they can be seen individually where they "die out" into the low bulk salinity middle section of the core (Figs. 3b, 4).
Brine drainage channels photographed by Cole and Shapiro (1998) show that these features may occur in almost the entire depth of sea ice up to $1.77 \mathrm{~m}$ thick and that the time required for their formation and development is integral to the evolution of the volume's 


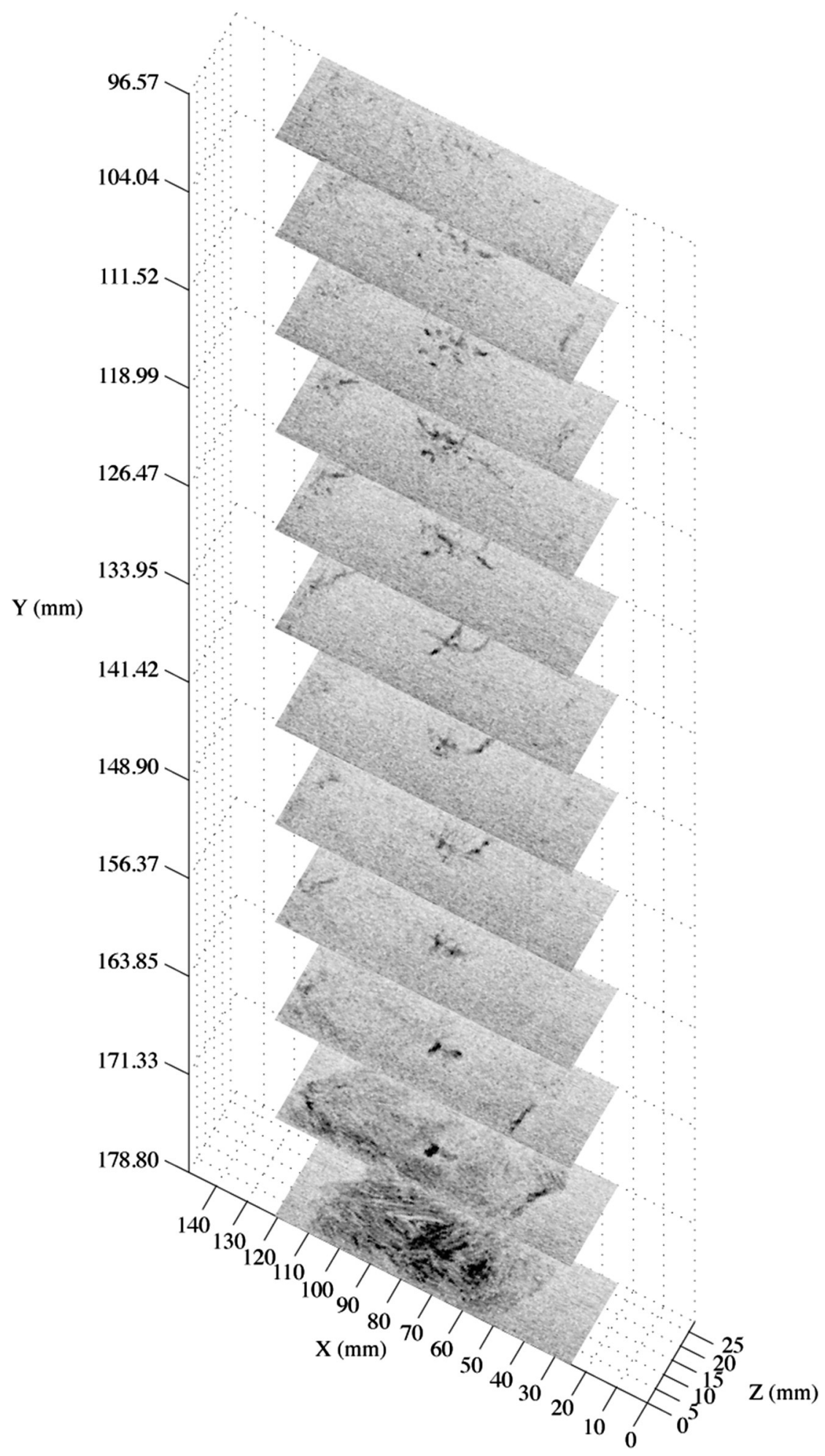

Fig. 5 (continued).

permeability. However, the central vertical channel of the brine drainage features observed by Cole and Shapiro (1998) are attended by feeder arms for nearly their whole length in the vertical, while the feeder arms observed in Fig. 5c and also by Lake and Lewis (1970) indicate that they attend the vertical channel as branches do a tree trunk, with only the central vertical channel or "trunk" present in the lower part of the brine drainage feature. These starburst shaped feeder arms which connect at $25-30^{\circ}$ to a main vertical channel affirm that some volume of sea ice (in this case slightly less than half the total thickness) may experience simultaneous horizontal and vertical brine movement.

The top 2-cm section of the sea ice had relative high bulk salinity on 20 January (Fig. 3b) likely due to the granular nature of the sea ice in this part of the core creating individual, vertically unconnected, spherical brine inclusions (e.g. Figs. 4, 5a) when combined with its growth 
history, relatively low temperature, rendered the top layer impermeable to vertical liquid transport. The 2-cm layers centered at 3,5 and $7 \mathrm{~cm}$ (Fig. 3b) were less saline due to the extended warm period in the middle of the experiment (Fig. 1) (see for e.g. Eicken, 1992). The increase in bulk salinity and brine volume in layers centered on 11 and $13 \mathrm{~cm}$ (Fig. 3b, c) likely occurred by rapid growth of the final $5.5 \mathrm{~cm}$ of sea ice between 16 and 20 January (Fig. 1). Finally, the bulk salinity and brine volume in the bottom 2 layers (Fig. 3b, c) are typical (e.g. Cox and Weeks, 1975) of a warm skeletal ice bottom (e.g. Fig. 2c) that was less than 2 days old (Fig. 1).

The morphology of the brine drainage channel feature presented here is instructive due to the size of the individual channels and their connection to the seawater below. In particular, brine supersaturated with $\mathrm{CO}_{2}$ (Papadimitriou et al., 2004), may lead to the precipitation of ikaite crystals (Rysgaard et al., 2012, 2014). The associated release of $\mathrm{CO}_{2}$ when ikaite precipitates may be rejected to the water column below due to the impermeability of the sea ice above this zone (e.g. Loose et al., 2011), which may explain the under-sea ice increase in $p \mathrm{CO}_{2}$ to near-saturation during winter observed by Else et al. (2012). Much of the young ice volume we sampled was cold enough $(<-2.2$ ${ }^{\circ} \mathrm{C}$ ) to produce ikaite crystals, and the observed brine drainage channel feature might offer them a mechanism by which to descend into the seawater below, taking their $\mathrm{CO}_{2}$-equivalent with them. The low concentrations of ikaite near the bottom of sea ice observed by Geilfus et al. (2013a) may therefore be due to either the lack of crystal formation or ikaite crystal export downward to the water column through these imaged channels. The attending channels to the main brine drainage channel range from 0.8 to $1.5 \mathrm{~mm}$ in diameter, which is greater than the ikaite crystal sizes of $<0.1 \mathrm{~mm}$ to $1 \mathrm{~mm}$ reported by Rysgaard et al. (2012) in Arctic sea ice, consistent with work showing that ikaite removal from sea ice through brine drainage is a process affecting the alkalinity of under-sea ice seawater and consequently affects oceanatmosphere $\mathrm{CO}_{2}$ exchange.

Using the premise that the highest MRI voxel value $\left(V_{\max }\right)$ indicates the presence of a completely liquid voxel, the liquid fraction $\left(L_{f}\right)$ profile calculated using Eq. 1 is presented in Fig. 6 along with a brine volume profile calculated using the in situ bulk salinity and the isothermal storage temperature $\left(-20^{\circ} \mathrm{C}\right.$ ) (Cox and Weeks, 1983) for comparison. The MRI-derived $L_{f}$ near the top of the core is slightly above $2 \%$ from where it decreases to $1.50 \%$ at $54.75 \mathrm{~mm}$ and then varies about $1.53 \%$ until $70.25 \mathrm{~mm}$ where it begins to increase. The $L_{f}$ reached $1.79 \%$ at $118.4 \mathrm{~mm}$ before it began to decrease to $1.65 \%$ at $159.5 \mathrm{~mm}$ (Fig. 6).

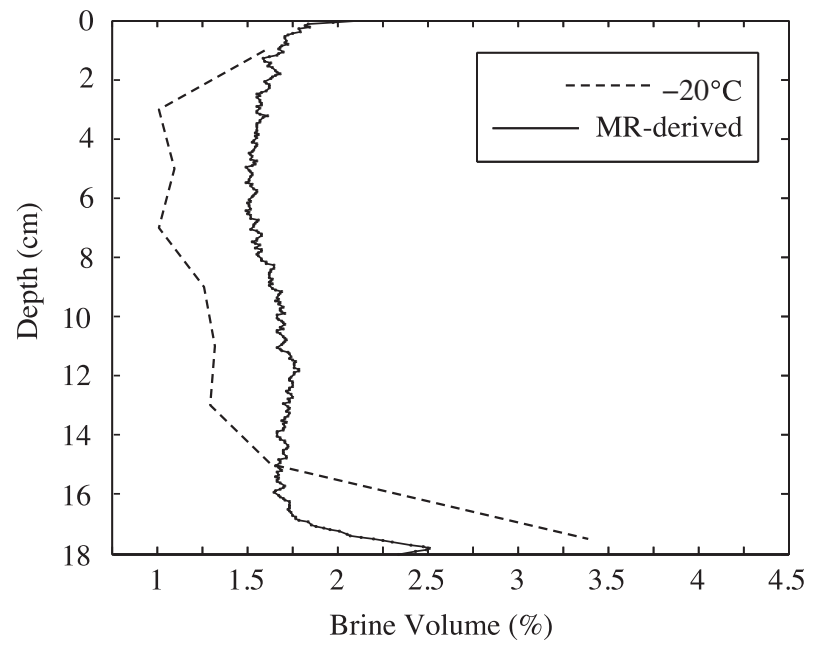

Fig. 6. The brine volume (after Cox and Weeks, 1983) calculated using the observed bulk salinity data (Fig. 3) and the sample storage temperature of $-20{ }^{\circ} \mathrm{C}$, to best approximate the brine volume of the sample as it was imaged by the MR scanner, and the liquid fraction at each of 290 rows ( 180.67 vertical $\mathrm{mm}$ ) derived from the MR image data normalized by the highest voxel value, $\mathrm{V}_{\max }$
Finally, just as the calculated brine volume profiles, the MRI-derived $L_{f}$ profile increased rapidly between $160 \mathrm{~mm}$ and the bottom of the core sample. The values of the MRI-derived $L_{f}$ profile are generally within $0.75 \%$ of the brine volumes calculated using the storage temperature and the shape of the two curves is similar, with the MR-derived curve even bearing an inflection toward higher values in the bottom half of the profile (Fig. 6). The shape of the MRI-derived liquid fraction profile (Fig. 6) is also similar to the calculated brine volume curve for the in situ temperatures (Fig. 3c).

\section{Conclusions}

Our results indicate that liquid inclusions, including first generation brine channels in young sea ice can be imaged very quickly ( 4 min $30 \mathrm{~s}$ ) in three-dimensions using a CISS gradient echo sequence, enabling quantification of the morphology of these liquid inclusions without the use of any special cooling infrastructure within the MR imager. The top and middle sections of the core sampled ( $100 \mathrm{~mm}$ depth from the ice surface) are not connected to the sea ice-seawater interface due to the spherical nature of the inclusions imaged and low liquid fraction; the low bulk salinity of the $5-10 \mathrm{~cm}$ section of our sample was due to warm sea ice temperatures following the formation of the first $12 \mathrm{~cm}$ of sea ice enabling desalination of the bottom half of the sea ice over that time. The imaged brine drainage channel feature pervades the bottom $43 \%$ of the young sea ice core sample thickness, and is $40 \mathrm{~mm}$ in the horizontal at its widest point. The feeder arms attend the main vertical channel at angles of $25-30^{\circ}$ from the vertical and do so above the bottom $30 \mathrm{~mm}$ of the sea ice. The diameter of these feeder arms falls between $0.8 \mathrm{~mm}$ and $1.5 \mathrm{~mm}$. The size and shape of the imaged brine drainage channel feature affirm that horizontal as well as vertical fluid permeability is possible within the bottom $80 \mathrm{~mm}$ of the sea ice core analyzed. The time it took for this feature to form was likely less than 6 days, concurrent with the formation of 6.5 of the bottom 8 centimeters of the sea ice in which it resided at the time of imaging. We conclude that simple, fast, MR imaging results in MR-derived brine volume estimates that match reasonably with empirically derived ones. This work should serve as an addition to the relatively sparse library of physical observations regarding the morphology and distribution of liquid inclusions in sea ice that are greatly influenced by the multitude of physical forcing scenarios which may occur over time both thermodynamically and dynamically and are vitally important in modeling studies.

\section{Acknowledgements}

The Canada Excellence Research Chair program (CERC, SR), the Canada Research Chair program (CRC, DB) and the Natural Sciences and Engineering Research Council (NSERC) of Canada (DB) contributed funding to this study. SERF was funded by the Canada Foundation of Innovation (CFI), the Canadian Excellence Research Chair program (SR), the Manitoba Research and Innovation Fund, and the University of Manitoba. We are grateful to Lawrence Ryner and Patricia Dreessen de Gervai for their time and willingness to attempt magnetic resonance imaging of an ice core without reservation. We thank $\mathrm{H}$. Eicken for his constructive comments. This work is a contribution to the Arctic Science Partnership (ASP) and the ArcticNet Networks of Centres of Excellence programs.

\section{References}

Assur, A., 1960. Composition of sea ice and its tensile strength. U.S. Army snow ice and permafrost research establishment, research report. 44. Corps of Engineers, Wilmette, Illinois (December 1960).

Aussilous, P., Sederman, A.J., Gladden, L.F., Huppert, H.E., Worster, M.G., 2006. Magnetic resonance imaging of structure and convection in solidifying mushy layers. J. Fluid Mech. 552, 99-125. http://dx.doi.org/10.1017/S0022112005008451.

Bennington, K.O., 1967. Desalination features in natural sea ice. J. Glaciol. 6 (48), 845-857. 
Bock, C., Eicken, H., 2005. A magnetic resonance study of temperature-dependent microstructural evolution and self-diffusion of water in Arctic first-year sea ice. Ann. Glaciol. 40, 179-184.

Callaghan, P.T., Dykstra, R., Eccles, C.D., Haskell, T.G., Seymour, J.D., 1999. A nuclear magnetic resonance study of Antarctic sea ice brine diffusivity. Cold Reg. Sci. Technol. 29, 153-171.

Cole, D.M., Shapiro, L.H., 1998. Observations of brine drainage networks and microstructure of first-year sea ice. J. Geophys. Res. 103 (C10), 21739-21750.

Cox, G.F.N., Weeks, W.F., 1975. Brine drainage and initial salt entrapment in sodium chloride ice. Cold Regions Research and Engineering Laboratory Research Report 345. Hanover, $\mathrm{NH}$.

Cox, G.F.N., Weeks, W.F., 1983. Equations for determining the gas and brine volumes in sea ice samples. J. Glaciol. 29, 306-316.

Cox, G.F.N., Weeks, W.F., 1986. Changes in the salinity and porosity of sea-ice samples during shipping and storage. J. Glaciol. 32 (112), 371-375.

Eicken, H., 1992. Salinity profiles of Antarctic sea ice: field data and model results. J. Geophys. Res. 97 (C10), 15545-15557.

Eicken, H., Bock, C., Wittig, R., Miller, H., Poertner, H.-O., 2000. Magnetic resonance imaging of sea-ice pore fluids: methods and thermal evolution of pore microstructure. Cold Reg. Sci. Technol. 31, 207-225.

Eicken, H., Grenfell, T.C., Perovich, D.K., Richter-Menge, J.A., Frey, K., 2004. Hydraulic controls of summer Arctic pack ice albedo. J. Geophys. Res. 109, C08007. http://dx.doi. org/10.1029/2003JC001989.

Eide, L.I., Martin, S., 1975. The formation of brine drainage features in young sea ice. J. Glaciol. 14 (70), 137-154.

Else, B.G.T., Papakyriakou, T.N., Galley, R.J., Mucci, A., Gosselin, M., Miller, L.A., Shadwick, E.H., Thomas, $\mathrm{H} ., 2012$. Annual cycles of $p \mathrm{CO}_{2 \mathrm{sw}}$ in the southeastern Beaufort Sea: new understandings of air-sea $\mathrm{CO}_{2}$ exchange in arctic polynya regions. J. Geophys. Res. 117, C00G13. http://dx.doi.org/10.1029/2011JC007346.

Fritsen, C.H., Lytle, V.I., Ackley, S.F., Sullivan, C.W., 1994. Autumn bloom of Antarctic packice algae. Science 266 (5186), 782-784.

Geilfus, N.-X., Carnat, G., Dieckmann, G.S., Halden, N., Nehrke, G., Papakyriakou, T., Tison, J.L., Delille, B., 2013a. First estimates of the contribution of $\mathrm{CaCO}_{3}$ precipitation to the release of $\mathrm{CO}_{2}$ to the atmosphere during young sea ice growth. J. Geophys. Res. 118, 1-12. http://dx.doi.org/10.1029/2012JC007980.

Geilfus, N.-X., Galley, R.J., Cooper, M., Halden, N., Hare, A., Wang, F., Søgaard, D.H., Rysgaard, S., 2013b. Gypsum crystals observed in experimental and natural sea ice. Geophys. Res. Lett. 40, 1-6. http://dx.doi.org/10.1029/2012GL058479.

Golden, K.M., Ackley, S.F., Lytle, V.I., 1998. The percolation phase transition in sea ice. Science 282, 2238. http://dx.doi.org/10.1026/science.282.5397.2238.

Golden, K.M., Eicken, H., Heaton, A.L., Miner, J., Pringle, D.J., Zhu, J., 2007. Thermal evolution of permeability and microstructure in sea ice. Geophys. Res. Lett. 34, L16501. http://dx.doi.org/10.1029/2007GL030447.

Hare, A.A., Wang, F., Barber, D., Geilfus, N.-X., Galley, R.J., Rysgaard, S., 2013. pH evolution in sea ice grown at an outdoor experimental facility. Mar. Chem. 154, 46-54. http:// dx.doi.org/10.1016/j.marchem.2013.04.007.

Hunke, E.C., Notz, D., Turner, A.K., M. Vancoppenolle, M., 2011. The multiphase physics of sea ice: a review for model developers. Cryosphere 5, 989-1009. http://dx.doi.org/10. 5194/tc-5-989-2011.

Hunter, M.W., Dykstra, R., Lim, M.H., Haskell, T.G., Callaghan, P.T., 2009. Using Earth's field NMR to study brine content in Antarctic sea ice: comparison with salinity and temperature estimates. Appl. Magn. Reson. 36, 1-8. http://dx.doi.org/10.1007/s00723009-0003-9.

Kovacs, A., 1996. Sea ice. Part I. Bulk salinity versus ice floe thickness. U.S. Cold Regions Research and Engineering Laboratory report 96-7. Hanover, NH (24 pages).

Krembs, C., Gradinger, R., Spindler, M., 2000. Implications of brine channel geometry and surface area for the interaction of sympagic organisms in Arctic sea ice. J. Exp. Mar. Biol. Ecol. 243, 55-80.

Lake, R.A., Lewis, E.L., 1970. Salt rejection by sea ice during growth. J. Geophys. Res. 75 (3), 583-597.
Light, B., Maykut, G.A., Grenfell, T.C., 2003. Effects of temperature on the microstructure of first-year Arctic sea ice. J. Geophys. Res. 108 (C2), 3051. http://dx.doi.org/10.1029/ 2001JC000887.

Loose, B., Miller, L.A., Elliott, S., Papakyriakou, T., 2011. Sea ice biogeochemistry and material transport across the frozen interface. Oceanography 24 (3), 202-218. http://dx. doi.org/10.5670/oceanog.2011.72.

Mercier, O.R., Hunter, M.W., Callaghan, P.T., 2005. Brine diffusion in first-year sea ice measured by Earth's field PGSE-NMR. Cold Reg. Sci. Technol. 42, 96-105.

Millero, F.J., 2006. Chemical Oceanography. 30. CRC Press.

Niedrauer, T.M., Martin, S., 1979. An experimental study of brine drainage and convection in young sea ice. J. Geophys. Res. 84 (C3), 1176-1186 (paper number 8C1208).

Notz, D., Worster, M.G., 2008. In situ measurements of the evolution of young sea ice J. Geophys. Res. 113, C03001. http://dx.doi.org/10.1029/2007JC004333.

Notz, D., Worster, M.G., 2009. Desalination processes of sea ice revisited. J. Geophys. Res. 114, C05006. http://dx.doi.org/10.1029/2008JC004885.

Notz, D., Wettlaufer, J.S., Worster, M.G., 2005. A non-destructive method for measuring the salinity and solid fraction of growing sea ice. J. Glaciol. 51 (172).

Oertling, A.B., Watts, R.G., 2004. Growth of and brine drainage from $\mathrm{NaCl}-\mathrm{H}_{2} \mathrm{O}$ freezing: a simulation of young sea ice. J. Geophys. Res. 109, C04013. http://dx.doi.org/10.1029/ 2001JC001109.

Papadimitriou, S., Kennedy, H., Kattner, G., Dieckmann, G.S., Thomas, D.N., 2004. Experimental evidence for carbonate precipitation and $\mathrm{CO}_{2}$ degassing during sea ice formation. Geochim. Cosmochim. Acta 68 (8), 1749-1761.

Pringle, D., Ingham, M., 2009. Thermal, electrical and hydraulic properties of sea ice. In: Eicken, H., Gradinger, R., Salganek, M., Shirasawa, K., Perovich, D., Leppäranta, M. (Eds.), Field Techniques for Sea Ice Research. University of Alaska Press, Fairbanks, AK.

Rysgaard, S., Glud, R.N., Lennert, K., Cooper, M., Halden, N., Leakey, R.J.G., Hawthorne, F.C., Barber, D., 2012. Ikaite crystals in melting sea ice-implications for $p \mathrm{CO}_{2}$ and $\mathrm{pH}$ levels in Arctic surface waters. Cryosphere 6, 1-8. http://dx.doi.org/10.5194/tc-6-1-2012.

Rysgaard, S., Wang, F., Galley, R.J., Grimm, R., Notz, D., Lemes, M., Geilfus, N.-X., Chaulk, A., Hare, A.A., Crabeck, O., Else, B.G.T., Campbell, K., Sørensen, L.L., Sieverts, J., Papakyriakou, T., 2014. Temporal dynamics of ikaite in experimental sea ice. Cryosphere 8, 1-10. http://dx.doi.org/10.5194/tc-8-1-2014.

Tucker, W.B.I., Perovich, D.K., Gow, A.J., Weeks, W.F., Drinkwater, M.R., 1992. Physical properties of sea ice relevant to remote sensing. Microwave Remote Sensing of Sea Ice. vol. 68. AGU, Washington, DC (Ch. 2).

Untersteiner, N., 1968. Natural desalination and equilibrium salinity profile of perennial sea ice. J. Geophys. Res. 73 (4), 1251-1257.

Vancoppenolle, M., Bitz, C.M., Fichefet, T., 2007. Summer landfast sea ice desalination at Point Barrow, Alaska: modeling and observations. J. Geophys. Res. 112, C04022. http://dx.doi.org/10.1029/2006JC003493.

Vancoppenolle, M., Meiners, K.M., Michel, C., Bopp, L., Brabant, F., Carnat, G., Delille, B. Lannuzel, D., Madec, G., Moreau, S., Tison, J.-L., van der Merwe, P., 2013. Role of sea ice in global biogeochemical cycles: emerging views and challenges. Quat. Sci. Rev. http://dx.doi.org/10.1016/j.quascirev.2013.04.011.

Weeks, W.F., Ackley, S.F., 1982. The growth, structure, and properties of sea ice. U.S. Army Cold Regions Research and Engineering Laboratory Monograph 82-1. Hanover, NH (130 pages)

Weeks, W.F., Ackley, S.F., 1986. The growth, structure and properties of sea ice. In: Untersteiner, N. (Ed.), The Geophysics of Sea ice. Plenum, New York, NY, pp. 9-164.

Wells, A.J., Wettlaufer, J.S., Orszag, S.A., 2011. Brine fluxes from growing sea ice. Geophys. Res. Lett. 38, L04501. http://dx.doi.org/10.1029/2010GL046288.

Wettlaufer, J.S., Worster, M.G., Huppert, H.E., 1997. Natural convection during solidification of an alloy from above with application to the evolution of sea ice. J. Fluid Mech. 344, 291-316 